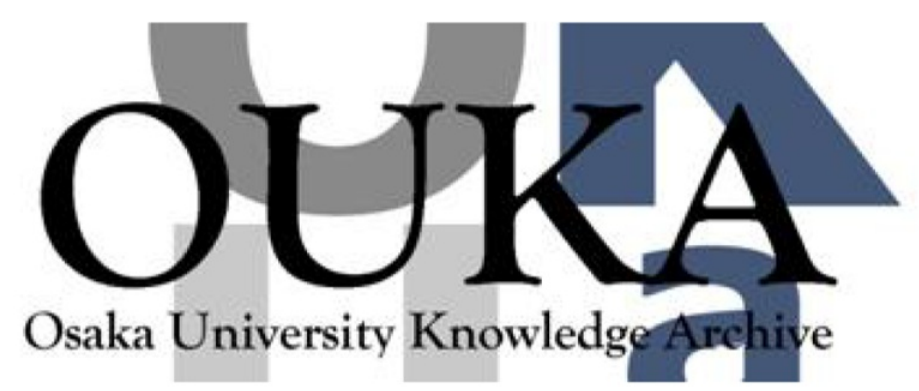

\begin{tabular}{|c|l|}
\hline Title & $\begin{array}{l}\text { Micro Welding of Thin Stainless Steel Foil with } \\
\text { a Direct Diode Laser }\end{array}$ \\
\hline Author(s) & $\begin{array}{l}\text { Abe, Nobuyuki; Funada, Yoshinori; Imanaka, } \\
\text { Takashi et al. }\end{array}$ \\
\hline Citation & Transactions of JWRI. 34(1) p. 19-p. 23 \\
\hline Issue Date & $2005-07$ \\
\hline oaire:version VoR \\
\hline URL & https://doi.org/10.18910/9012 \\
\hline rights & \\
\hline Note & \\
\hline
\end{tabular}

Osaka University Knowledge Archive : OUKA

https://ir. Library. osaka-u. ac. jp/

Osaka University 
Transactions of JWRI, Vol. 34 (2005), No. 1

\title{
Micro Welding of Thin Stainless Steel Foil with a Direct Diode Laser ${ }^{\dagger}$
}

\author{
ABE Nobuyuki*, FUNADA Yoshinori**, IMANAKA Takashi***, TSUKAMOTO Masahiro****
}

\begin{abstract}
Recently, industrial product parts and components are being made smaller to reduce energy consumption and save space, creating a growing need for the micro-welding of thin foil less than $100 \mu$ m thick. For this purpose, laser processing is expected to be the method of choice because it allows more precise heat control compared with arc and plasma processing. In this report, the practicability of welding thin stainless steel foil with a direct diode laser system was investigated. The elliptically shaped laser beam of the direct diode laser enabled successful butt-welding of thin stainless steel foil $100 \mu \mathrm{m}$ and less in thickness. At a output power of $100 \mathrm{~W}, 100 \mu \mathrm{m}$ and $50 \mu \mathrm{m}$ thick foils could be welded at a high speed of $6.0 \mathrm{~m} / \mathrm{min}$ and $18.0 \mathrm{~m} / \mathrm{min}$, respectively. They had narrow bead widths of $100 \mu \mathrm{m}$ which was narrower than the beam size of the laser. No spatter or plasma plume was observed when welding without an assist gas. The tensile strength of the weld bead was nearly the same as that of the base material.
\end{abstract}

KEY WORDS: (Diode Laser), (Micro Welding), (Thin Foil), (Butt Welding), (High Speed Welding)

\section{INTRODUCTION}

In the electronics and precision machining industries many parts, such as pressure sensors with diaphragms, bellows and steel belts, are manufactured by welding together thin metallic sheets. Recently, such parts and components are being made smaller to increase their energy efficiency and achieve greater compactness. This has created the need for an advanced welding method suitable for thin foil $100 \mu \mathrm{m}$ or less in thickness. It is difficult to weld such thin foil using an ordinary processing method such as arc welding or plasma welding, as molten metal is likely to drop down before solidification due to the wide heated area. Thin foil welding requires a heat source that heats a smaller area. Laser heat sources heat a smaller area because of their ability to be finely focused. However, $\mathrm{CO}_{2}$ lasers, $\mathrm{Nd}$ :YAG lasers and other commonly used laser systems have the drawback of low energy conversion efficiency.

Diode lasers offer many advantages including high conversion efficiency, small size, and a long lifetime. The authors previously applied a high power $2 \mathrm{~kW}$ class diode laser to the welding of metallic sheets ranging in thickness from $150 \mu \mathrm{m}$ to $3 \mathrm{~mm}^{1,2)}$. However, it was difficult to weld thin foil below $100 \mu \mathrm{m}$ in thickness, most probably due to the fact that high power diode lasers employing an optical fiber have a circular beam shape; at

\footnotetext{
† Received on July 1, 2005

* Associate Professor

** Industrial Research Institute of Ishikawa

*** Graduate Student

**** Assistant Professor
}

a low power density, the beam is too large to weld thin foil, while if a finely focused beam is used the power density becomes too high resulting in plasma formation and welding defects. Direct diode lasers without an optical fiber have an elliptical beam shape which is effective in the formation of a narrow bead with high heat input without plasma formation and welding defects. In this paper, a welding system for thin foils was manufactured consisting a 500W class diode laser without an optical fiber, and the practicability of an elliptical direct beam from it was investigated for welding thin stainless steel foil $100 \mu \mathrm{m}$ and $50 \mu \mathrm{m}$ in thickness.

\section{EXPERIMENTAL APPARATUS}

\subsection{Direct diode laser micro-welding system}

The micro-welding system used for test welding of thin foil is shown in Fig. 1. It consists of a micro-positioning stage, a micro-monitor system and a direct diode laser with a maximum output power of 500W and a wavelength of $808 \mathrm{~nm}$. The laser head is $\phi 65 \mathrm{~mm}$ $\mathrm{x} 300 \mathrm{~mm}$ and weighs $2 \mathrm{~kg}$. The micro-positioning stage and micro-monitor system are used for precisely aligning the laser beam along a contact line of specimens. Specimens were directly irradiated at a normal angle without an optical fiber.

The output characteristics of the laser head were

Transactions of JWRI is published by Joining and Welding Research Institute, Osaka University, Ibaraki, Osaka 567-0047, Japan 


\section{Micro Welding of Thin Stainless Steel Foil with a Direct Diode Laser}

measured with a power meter. The output power increased proportionally to the input current as shown in Fig. 2 (a). The beam profile was measured using a beam profiler. Figure 2 (b) shows the beam profile at the focal point. The shape of the beam was elliptical, and the beam size was $0.3 \times 1.8 \mathrm{~mm}$. The mean power density at the maximum power of $500 \mathrm{~W}$ was $92 \mathrm{~kW} / \mathrm{cm}^{2}$. The work distance between specimen and the laser head was $47 \mathrm{~mm}$.

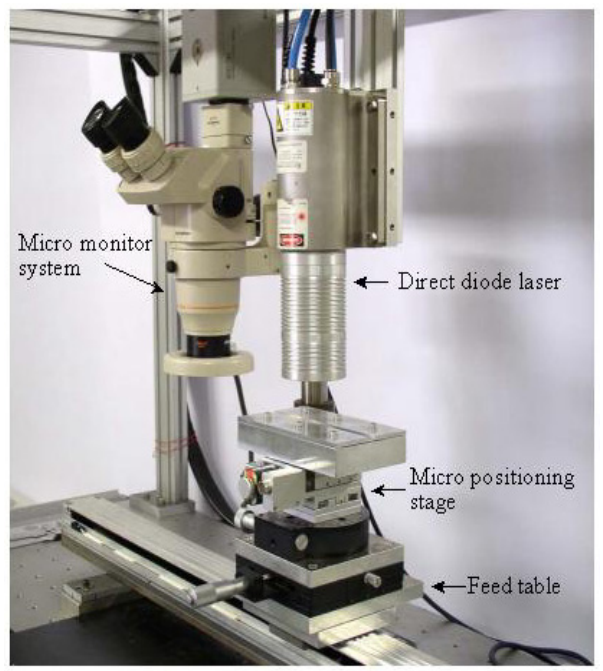

Figure 1 Micro-welding system with diode laser

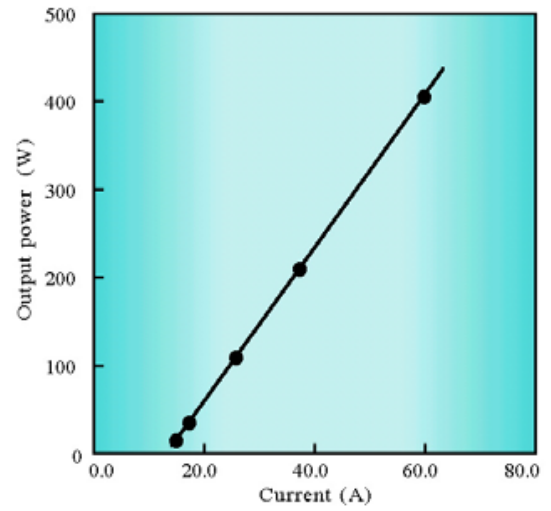

(a) P-I characteristic

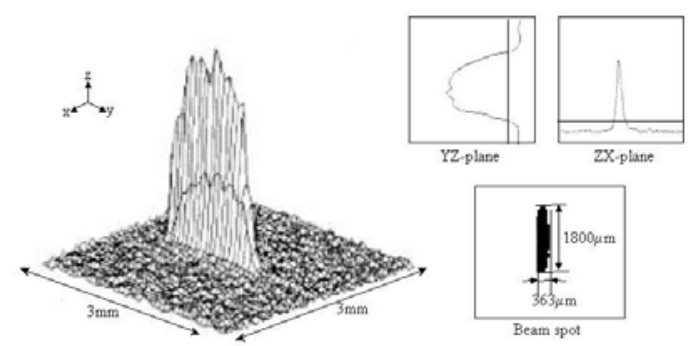

(b) Beam profile

Figure 2 P-I characteristic and beam profile at focal point

\subsection{Specimen, welding conditions and evaluation method}

The specimens used were stainless steel foil (SUS304H) $100 \mu \mathrm{m}$ and $50 \mu \mathrm{m}$ in thickness. The length and width were $70 \mathrm{~mm}$ and $12.5 \mathrm{~mm}$, respectively. Their edges were finished by grinding as shown in Fig. 3, so that the two specimens made good contact with each other without a gap. The specimens were fixed on the micro-positioning stage using welding jigs. The contact line was precisely aligned with the irradiation point of the beam and positioned parallel to the long axis of the beam with the micro-monitor system. The micro-positioning stage traveled parallel to the long axis of the elliptical beam as shown in Fig. 4. The laser beam irradiated the surface of the specimens at the focal point under the welding conditions as shown in Table 1.

Cross sections of the weld beads were polished and electrochemically etched and observed using an optical microscope. The tensile strength of the weld beads was evaluated with a tensile strength tester.

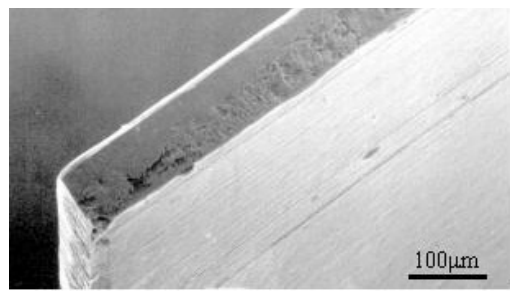

(a) $100 \mu \mathrm{m}$ thick foil

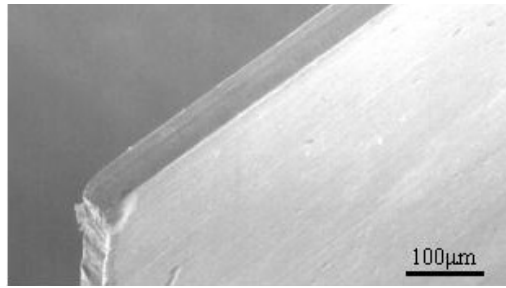

(b) $50 \mu \mathrm{m}$ thick foil

Figure 3 SEM images of edges of $50 \mu \mathrm{m}$ and $100 \mu \mathrm{m}$ thick foils used for welding test.

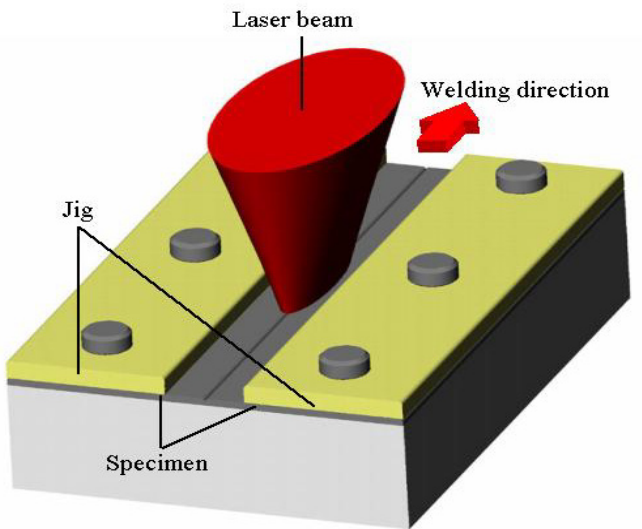

Figure 4 Schematic illustration of micro- welding with elliptical laser beam. 
Table 1 Welding conditions

\begin{tabular}{lll}
\hline Thickness $(\mu \mathrm{m})$ & $\begin{array}{l}\text { Output } \\
(\mathrm{W})\end{array}$ & $\begin{array}{l}\text { power } \\
(\mathrm{m} / \mathrm{min})\end{array}$ \\
\hline \multirow{3}{*}{50} & 50 & $4.5-9.0$ \\
& 75 & $9.0-15.0$ \\
& 100 & $13.5-19.5$ \\
\hline \multirow{3}{*}{100} & 100 & $2.1-7.5$ \\
& 200 & $7.5-15.0$ \\
& 300 & $12.0-22.5$ \\
\hline
\end{tabular}

\section{RESULTS AND DISCUSSION}

\subsection{Appearance of weld bead}

Figure 5 shows optical microscope photographs of front and rear appearance of the weld beads of $100 \mu \mathrm{m}$ thick foil specimens welded at various speeds at output powers $100 \mathrm{~W}$ and $300 \mathrm{~W}$. At an output power of $100 \mathrm{~W}$, a sound bead was formed in the range from 3.0 to $6.0 \mathrm{~m} / \mathrm{min}$. At welding speed faster than $7.5 \mathrm{~m} / \mathrm{min}$, no weld bead could be observed on the rear face. In contrast, holes were observed in the weld bead at welding speeds slower than $2.1 \mathrm{~m} / \mathrm{min}$. It is conceivable that the holes in the weld bead were caused by condensation of the molten metal due to surface tension. There are optimum weldable speed ranges for laser powers. At an output power of $300 \mathrm{~W}$, a sound bead was formed in the range from 13.5 to $21.0 \mathrm{~m} / \mathrm{min}$. At welding speeds slower than $12.0 \mathrm{~m} / \mathrm{min}$, holes were observed, and at welding speeds faster than $22.5 \mathrm{~m} / \mathrm{min}$, no weld bead could be obtained on the rear face.

Figure 6 shows optical microscope photographs of front and rear appearance of the weld beads of $50 \mu \mathrm{m}$ thick foil specimens welded at various speeds and output powers of $50 \mathrm{~W}$ and $100 \mathrm{~W}$. At an output power of $100 \mathrm{~W}$, the foils could be welded in the range from 15.0 to $18.0 \mathrm{~m} / \mathrm{min}$. The welding speed range was shifted toward higher speed compared with $100 \mu \mathrm{m}$ thick foils. In the case of $50 \mu \mathrm{m}$ foil welding, a sound bead could be obtained in the range from 6.0 to $7.5 \mathrm{~m} / \mathrm{min}$ at an output power of $50 \mathrm{~W}$, that is, an extremely lower power density of $9.2 \mathrm{~kW} / \mathrm{cm}^{2}$. These results confirmed that sound butt-welding of $100 \mu \mathrm{m}$ and $50 \mu \mathrm{m}$ thick foil was possible with a direct diode laser.

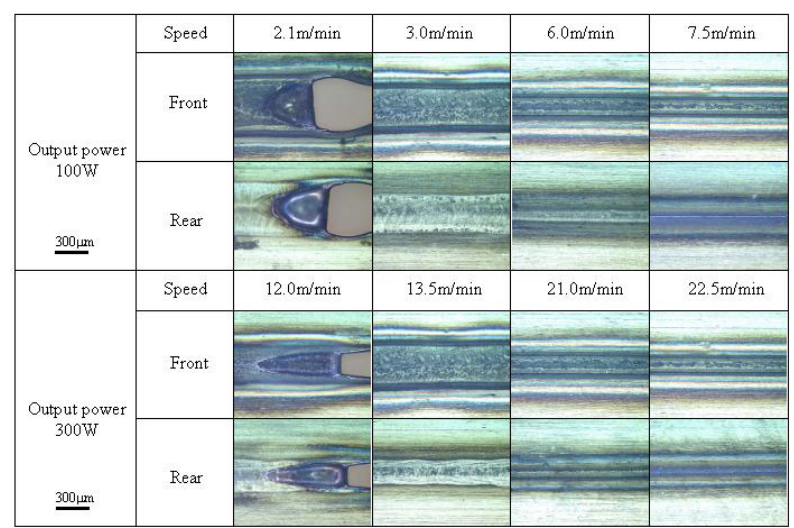

Figure 5 Microscope photographs of front and rear faces of weld beads of $100 \mu \mathrm{m}$ foil.

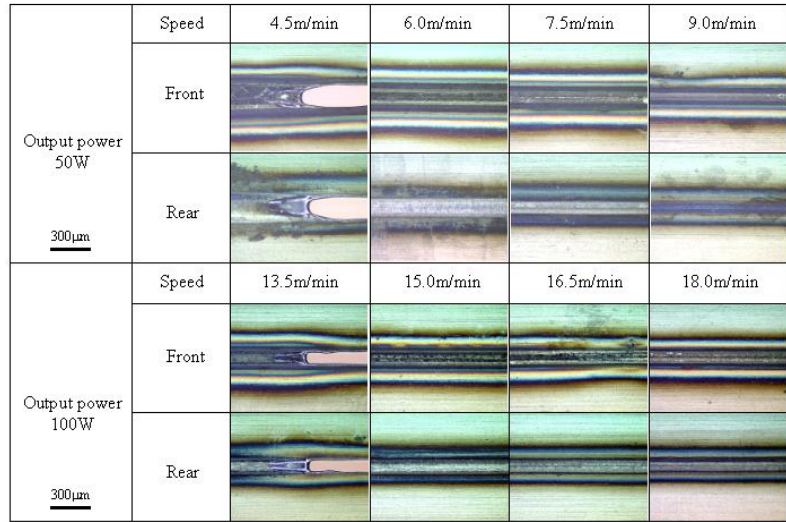

Figure 6 Microscope photographs of front and rear faces of weld beads of $50 \mu \mathrm{m}$ foil.

\subsection{Weldable speed area for thin foils}

Figure 7 shows the weldable speed areas of $100 \mathrm{~mm}$ and $50 \mathrm{~mm}$ thick foils against output power. At an output power of $300 \mathrm{~W}$, the weldable speed range for $100 \mu \mathrm{m}$ thick foil is 13.5 to $21.0 \mathrm{~m} / \mathrm{min}$. However, it narrows to between 3.0 and $6.0 \mathrm{~m} / \mathrm{min}$ at a lower output power of $100 \mathrm{~W}$. In the case of $50 \mu \mathrm{m}$ thick foils, the weldabe speed range at an output power of $100 \mathrm{~W}$ is 15.0 to $18.0 \mathrm{~m} / \mathrm{min}$. However, it narrows to between 6.0 and $7.5 \mathrm{~m} / \mathrm{min}$ at a lower output power of $50 \mathrm{~W}$. The weldable speed range becomes narrower with decreasing output power.

$100 \mu \mathrm{m}$ thick foils could be welded within a speed range of 13.5 to $21.0 \mathrm{~m} / \mathrm{min}$ at an output power of $300 \mathrm{~W}$. $50 \mu \mathrm{m}$ thick foils could be welded at a similarly high speed at an output power of $100 \mathrm{~W}$, but the weldable speed range was narrowed to between 15.0 and $18.0 \mathrm{~m} / \mathrm{min}$. The weldable speed range further narrowed to between $6.0 \mathrm{~m} / \mathrm{min}$ and $7.5 \mathrm{~m} / \mathrm{min}$ at an output power of 50W. From these results it was concluded that decreasing output power and decreasing foil thickness narrow the weldable speed range. Therefore, more precise control of the welding conditions including both welding speed and output power will be required for thinner foils, such as the $20 \mu \mathrm{m}$ thickness used for a pressure sensor.

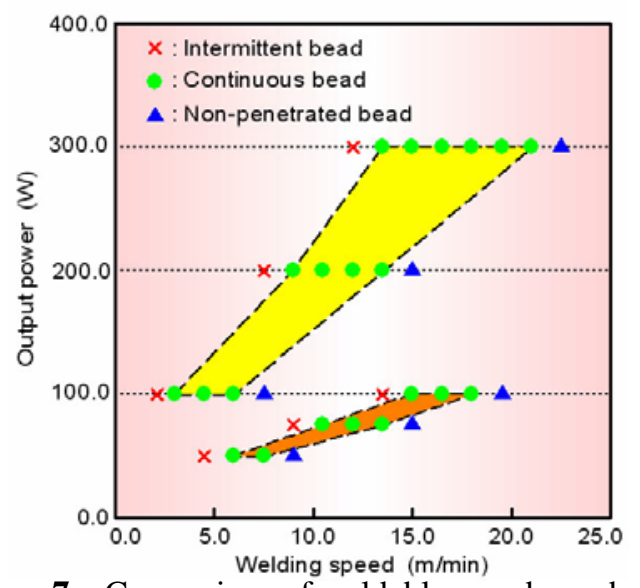

Figure 7 Comparison of weldable speed area between $100 \mu \mathrm{m}$ thick foil and $50 \mu \mathrm{m}$ thick foil 


\section{Micro Welding of Thin Stainless Steel Foil with a Direct Diode Laser}

\subsection{Cross section of weld bead}

Figure 8 (a) and (b) show optical microscope photographs of cross sections of weld beads of $100 \mu \mathrm{m}$ and $50 \mu \mathrm{m}$ thick foil at an output power of $100 \mathrm{~W}$. The cross section has a heat conducting type bead shape rather than the keyhole type which is seen in $\mathrm{CO}_{2}$ or $\mathrm{Nd}$ :YAG laser welding. It was found that the thin foil welding was possible with a direct diode laser which has lower power density than $\mathrm{CO}_{2}$ or $\mathrm{Nd}$ :YAG laser welding. The lower power density results in very calm welding that forms smooth beads even without an assist gas. This strongly suggests that a direct diode laser is much more suitable for thin foil welding than $\mathrm{CO}_{2}$ laser or Nd:YAG laser.

Figure 9 shows the overview of $50 \mu \mathrm{m}$ thick foils welded at an output power of $75 \mathrm{~W}$ and a welding speed of $10.5 \mathrm{~m} / \mathrm{min}$. The welded specimen has very smooth weld bead with little distortion. Welding of $50 \mu \mathrm{m}$ thick foils was possible using an elliptical beam produced by a direct diode laser with a power density of $13.7 \mathrm{~kW} / \mathrm{cm}^{2}$, and contributed to a narrow weld bead width, and avoidance of thermal distortion.

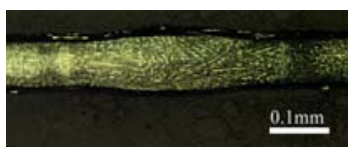

$3.0 \mathrm{~m} / \mathrm{min}$

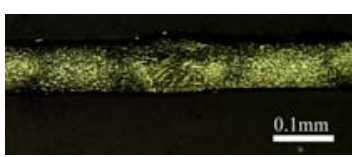

$6.0 \mathrm{~m} / \mathrm{min}$

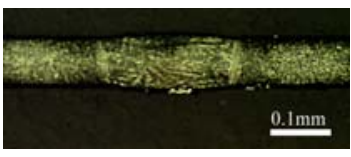

$4.5 \mathrm{~m} / \mathrm{min}$

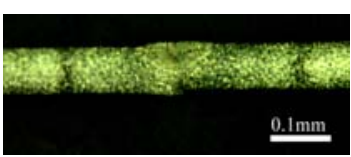

$7.5 \mathrm{~m} / \mathrm{min}$ (a) $100 \mu \mathrm{m}$ thick foils

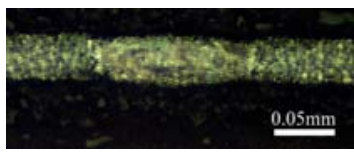

$15.0 \mathrm{~m} / \mathrm{min}$

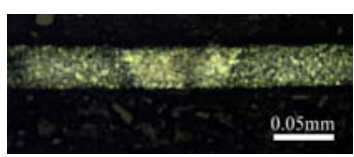

$18.0 \mathrm{~m} / \mathrm{min}$

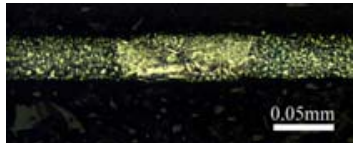

$16.5 \mathrm{~m} / \mathrm{min}$

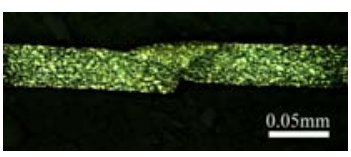

$19.5 \mathrm{~m} / \mathrm{min}$ (b) $50 \mu \mathrm{m}$ thick foils

Figure 8 Cross-sections of weld beads of $100 \mu \mathrm{m}$ and $50 \mu \mathrm{m}$ in thickness at an output power of $100 \mathrm{~W}$.

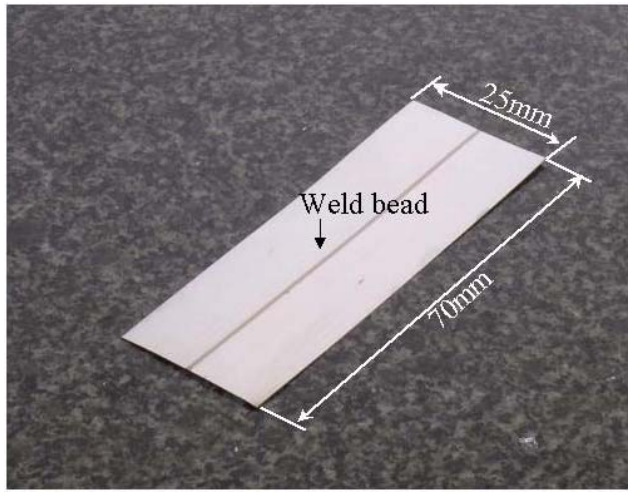

Figure 9 Overview of a welded foil of $50 \mu \mathrm{m}$ in thickness at an output power of $75 \mathrm{~W}$ and a welding speed of $10.5 \mathrm{~m} / \mathrm{min}$.

\subsection{Observation of welding phenomena}

The phenomena during thin foil welding were observed from the front of the welding direction using a CCD camera. Figure 10 shows a typical photograph taken during welding at an output power of $75 \mathrm{~W}$ and a welding speed of $10.5 \mathrm{~m} / \mathrm{min}$.

The bright spot at the center of the photograph is the laser irradiation area. It shows the shape of the molten metal produced by irradiation with the laser beam, whose width is much narrower than $1 \mathrm{~mm}$. This is due to the elliptical beam shape of the direct diode laser which irradiates the contact line of the specimen with its long axis.

Neither spatter nor plasma plume were observed around this area, even though no assist gas nor shield gas was used. It was found that the welding phenomena with the direct diode laser were quite calm. The lower power density of diode lasers as compared to $\mathrm{CO}_{2}$ lasers and Nd:YAG lasers contributes to the calm welding phenomena, with the result that there is no spatter or plasma plume.

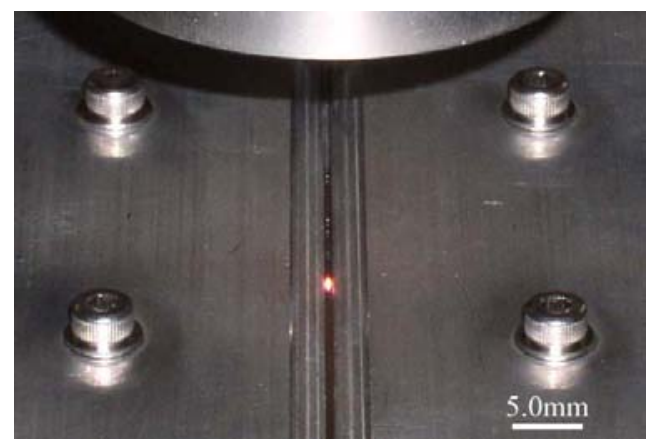

Figure 10 Laser irradiation speed situation during welding of foil $50 \mu \mathrm{m}$ in thickness at the output power of $75 \mathrm{~W}$ and the welding speed of $10.5 \mathrm{~m} / \mathrm{min}$. 


\subsection{Tensile strength of welded foil}

In order to evaluate the tensile strength of the welded foil, tensile fracture tests were carried out. The results are shown in Table 2 for welded thin foils of $50 \mu \mathrm{m}$ in thickness at typical combinations of output power and welding speed which produced sound beads. The mean tensile strength was more than $1200 \mathrm{MPa}$, which is nearly equal to the nominal strength of SUS304H.

Figure 11 shows a typical cross section of a fractured sample. The fracture occurred not in the bead, but rather in the heat affected zone due to the fact that direct diode laser welding produces a smooth bead with no defects produced by the welding.

\subsection{Critical width of weld bead}

Figure 12 (a) and (b) show the relationship between the bead width and welding speed at several output powers when welding $100 \mu \mathrm{m}$ and $50 \mu \mathrm{m}$ thick foil, respectively. The bead width drastically decreased with increasing welding speed. In the case of $100 \mu \mathrm{m}$ thick foil, a full penetration continuous bead was obtained at $100 \mathrm{~W}$ when the bead width was less than $300 \mu \mathrm{m}$. When the bead width was more than $300 \mu \mathrm{m}$, an intermittent bead was formed due to condensation of the molten metal. In the case of $50 \mu \mathrm{m}$ thick foil, a bead width below $150 \mu \mathrm{m}$ was required for obtaining a continuous bead. These widths can be thought as the critical widths below which a continuous bead was obtained. The critical widths were three to four times larger than the foil's thickness.

Table 2 Tensile strength of weld beads of $50 \mu \mathrm{m}$ thick foil

\begin{tabular}{lll}
\hline $\begin{array}{l}\text { Output } \\
\text { (W) }\end{array}$ & $\begin{array}{l}\text { Welding } \\
(\mathrm{m} / \mathrm{min})\end{array}$ & speed \\
\hline 50 & 7.5 & 1223 \\
75 & 10.5 & 1287 \\
100 & 16.5 & 1241 \\
\hline
\end{tabular}

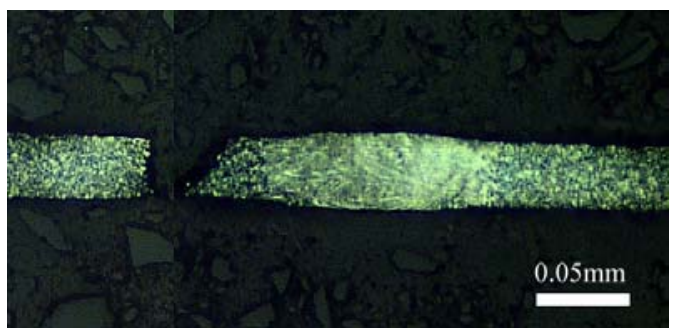

Figure 11 Microscope photograph of cross-section of fractured $50 \mu \mathrm{m}$ thick foil welded at an output power of $75 \mathrm{~W}$ and welding speed of $10.5 \mathrm{~m} / \mathrm{min}$
Formation of an intermittent weld bead is caused by condensation of the molten metal due to surface tension. The change in welding phenomena from a continuous bead to an intermittent bead occurs when the surface area of the rectangular molten pool becomes larger than that of spherically condensed molten metal as shown in the upper illustration in Figure (a). If it is assumed that the width of the rectangular molten pool produced by the elliptical beam is equal to the diameter of the spherically condensed molten metal, the rectangular molten pool's surface area will become larger than that of the spherically condensed molten metal when the rectangular molten pool's width exceeds three times its thickness. It is thought that an intermittent bead is formed when the bead width exceeds three times the foil's thickness as shown in Fig. 12. Therefore, in order to weld thin foil with a full-penetrated weld bead, its width must be below the three or four times of the thickness.

\section{CONCLUSION}

Butt-welding of $100 \mu \mathrm{m}$ and $50 \mu \mathrm{m}$ thick stainless steel foil (SUS304H) was investigated using a 500W class direct diode laser with a beam size of $0.3 \times 1.8 \mathrm{~mm}$ and a maximum power density of $91 \mathrm{~kW} / \mathrm{cm}^{2}$. The following results were obtained.

(1) The direct diode laser was able to weld $50 \mu \mathrm{m}$ thick foil at a high speed of $18.0 \mathrm{~m} / \mathrm{min}$ with an output power of $100 \mathrm{~W}$.

(2) The bead shape was heat conduction welding type.

(3) The welding phenomena with a direct diode laser were very calm, and no spatter or plasma plume generation was observed even without an assist gas.

(4) The tensile strength of the welded foil was nearly equal to the nominal value of the base material.

(5) In order to weld thin foil, the bead width must be narrower than three times the foil thickness. A direct diode laser was able to form such a narrow bead through precision control of the output power and welding speed.

\section{ACKNOWLEDGMENTS}

The authors would like to express many thanks to Mr. H. Mamezuka for his invaluable contribution in conducting the experiments

\section{REFERENCES}

1) N. Abe, R. Higashino, M. Tsukamoto, S. Miyake and S. Noguchi: Proc. ICALEO’99, 1999; A236.

2) N. Abe, R. Higashino, N. Nakagawa, M. Tsukamoto, S. Miyake, S. Noguchi and M. Hayashi: Proc. ICALEO 2000, 2000; A16. 